\title{
Nuclear winter expert vanishes without trace
}

\section{Stockholm}

A SOVIET computer scientist, who has played a leading part in the nuclear winter debate, disappeared from a meeting in Toledo, Spain, last March, and is now feared by Western colleagues to be dead. Vladimir Aleksandrov was a Soviet delegate to SCOPE (the Scientific Committee on Problems of the Environment) and was an active participant in the SCOPE working party on the environmental effects of nuclear warfare.

Reports of last sightings of Aleksandrov vary, but according to one account he expressed his intention of going back to the meeting centre and was never seen again. According to another source, he was last seen being bundled into a car by several men. His personal effects were later found to have gone from his room, but his passport was found in a litter bin.

Former colleagues at the Lawrence Livermore Laboratories in California report frantic messages from Mrs Aleksandrov, who was greatly surprised and concerned at her husband's failure to return.

Aleksandrov was the author of the Soviet computer model using a two-layer model of atmospheric circulation which was presented in Stockholm in November 1983, and which supported the conclusions of Sagan and Ehrlich on the climatic aftermath of a nuclear war. Aleksandrov had allegedly told a Western colleague that he had been told to "get busy" on nuclear winter two months before the Sagan "peer review" meeting at the American Academy of Arts and Sciences in Boston in April 1983.

Aleksandrov had, during the past eighteen months, gradually been replaced as the chief Soviet scientific spokesperson on nuclear winter by Kiril Kondrat'ev, whose papers concentrated on nitrous oxides and trace gas effects, and paid little heed to smoke and dust. This may mean nothing more, however, than that once the computer model was complete, the Hydrometeorological Institute of the Soviet Academy took over the main burden of the nuclear winter campaign.

The silence of Aleksandrov's Western colleagues is difficult to explain. Some, however, seem to have thought that he had defected, and that the car incident was a cover-up. These have expected him to emerge from a safe house in some Western country in due course. But in that case, protest from the Soviet Union about what could well be interpreted as a kidnapping would have been expected, but none has been forthcoming. Nor have there been attemps to brand Aleksandrov as a defector. One source which claims to be in contact with several Western intelligence services says that it is "not on the cards that the West has him".

If Aleksandrov was repatriated to the Soviet Union by force, as some of his friends now fear, and he was killed either deliberately or in the course of such an attempt, it is not clear what the motive could have been. One suggestion is that he was feared to be a defection risk. Another is that Aleksandrov had become convinced that the Soviet concern with nuclear winter was merely for public and international opinion and that the Soviet military planners were working on the basis of a "survivable level" of fall-out, and that he intended to voice these views.

Such suggestions, perhaps farfetched, reveal the growing concern about his fate. Hopefully, however, even at this late date, the Soviet Union or some Western government will respond with some explanation and, if possible, the production of Aleksandrov in person.

Vera Rich

\section{Nuclear power}

\section{US plans to set industry free}

\section{Washington}

ATteMPTs are again being made to revitalize the moribund US nuclear power industry by speeding up the licensing of new plants. Three bills* now before Congress, from the Department of Energy, the Nuclear Regulatory Commission (NRC) and from the industry itself, seek to encourage the use of standard plant designs by giving NRC authority to issue combined construction and operating licences (COLs) at the design stage. At present, NRC must hold a second examination of safety issues before a completed plant can be operated.

The argument is that by forcing all safety issues into a single examination, NRC will give utilities an incentive to perfect complete designs that can be adapted to the requirements of different sites. Construction permits have often been issued for incomplete plans, an approach characterized by the Union of Concerned Scientists (UCS) as "design-as-you-go", resulting in frequent expensive modifications.

There is widespread agreement that the present two-step licensing procedure is inefficient, and that engineering expertise would be better used if there were but a few standard plant designs to be examined. But opponents of the new proposals argue that they fail to encourage standard designs, and that they make it harder to raise serious safety problems once a plant has been built.

Each of the bills recognizes that some kind of pre-operational safety review is necessary before operations can begin, but to prevent determined opponents of a plant from raising questions of safety that have been adequately considered at the design stage, each contains some restriction on the issues that can be raised in a pre-operational review. The NRC bill, for example, says a new issue must be a substantial dispute of fact that cannot be resolved except at a hearing, and that it must either concern non-compliance with a previously-issued COL or a question that could not previously have been examined. Controversially, the NRC bill also says that for a post-construction modification to be required, it must substantially improve the overall safety of the facility. Overall safety is examined using probabilistic risk assessment, which according to its critics is nothing better than an obfuscatory device that, by being easily manipulable, is used to give spurious authority to safety claims. The NRC bill also raises hackles because it would allow a plant to begin operating before hearings end.

The Department of Energy's bill would make it even harder for safety issues to be introduced retrospectively, as it would allow NRC to make conclusive design approvals that would remain in force for 10 years no matter what information was subsequently discovered; furthermore, it would allow the licensee to deviate from the design in the COL as the licensee saw fit. The industry bill gives intervenors greater latitude to introduce safety issues at a late stage, but requires NRC to perform a central review before incorporating changed requirements. This could mean delays of years.

Opposition to the three bills, voiced more articulately by UCS, focuses on the argument that NRC already has the legal authority to approve standardized plant designs. UCS says it is the fault of the industry that such designs have not been used in the past, because it has sought construction permits on the basis of an examination of very incomplete plans. According to UCS, the depressed state of the industry - no new plants ordered since 1978 - would change if NRC insisted on seeing a complete design before granting construction approval. Industry spokesmen contritely acknowledge that approval of incomplete plans is counterproductive and promise that utilities will submit "essentially complete" plans in future Tim Beardsley

${ }^{*}$ HR 1029 (from the industry) and HR 1447 (from NRC); the Department of Energy bill has not yet formally been introduced in the 99 th Congress. 